\title{
SPATIALIZING OPEN DATA FOR THE ASSESSMENT AND THE IMPROVEMENT OF TERRITORIAL AND SOCIAL COHESION
}

\author{
F. Scorza ${ }^{\mathrm{a}}$, G.B. Las Casas ${ }^{\mathrm{a}}$, B. Murgante ${ }^{\mathrm{a}, *}$ \\ ${ }^{\text {a }}$ School of Engineering, University of Basilicata, 10, Viale dell'Ateneo Lucano 85100 - Potenza - Italy - \\ francescoscorza@gmail.com, (lascasas, murgante)@unibas.it
}

KEY WORDS: Territorial specialization, New Cohesion Policy, Regional Development, Impact assessment, Open Data, OpenCohesion

\begin{abstract}
:
An integrated place-based approach for the improvement of territorial and social cohesion is the new instance for planning disciplines, coming from EU New Cohesion Policies. This paper considers the territorial impact assessment of regional development policies as a precondition in order to develop balanced and effective operative programs at national and regional levels. The contribution of 'open data' appears to be mature in order to support this application and in this paper we present a spatial analysis technique for the evaluation of EU funds effects at territorial level, starting from open data by Open Cohesion. The application is focused on internal areas of Basilicata Region: Agri river Valley. A complex contest, where environmental and agricultural traditional vocations conflict with a recent development of oil extraction industries. Conclusions concern further applications and perspectives to improve and support regional development planning considering the exploitation of open data sources and spatial analysis.
\end{abstract}

\section{INTRODUCTION}

The perspective of an integrated place-based approach for the improvement of territorial and social cohesion, strongly promoted in the framework of The New Cohesion Policy and Europe 2020 agenda, reinforces the scientific and technical debate concerning planning tools and practices (Las Casas, Scorza 2016), monitoring/assessment systems, governance models at regional and sub-regional level. Smart growth, sustainable growth and inclusive growth for EU 2020 represent overall goals to be achieved under the comprehensive approach defined by Barca (2009) as a 'place based approach'. As the authors already discussed in previous works (Las Casas, Scorza, 2009) concerning the issue of territorial impact assessment of regional development policies, the relevant instance comes from knowledge management in regional programming practice. It means data availability, open access to datasets in "nearly realtime", participation, knowledge sharing, key actors effective involvement in planning processes.

The "concentration" issue coming from EU 2020 Cohesion Policy still reflects ambiguity in interpretation (Capello, 2014) and not structured implementation in Regional Programs. From a "thematic concentration" to a "spatial concentration", several attempts are going to be developed in an uncertainty framework. If a "thematic concentration" reflects more a traditional approach considering a panel of main objectives and goals, it could represents an effective procedure if a proper context analysis identified ex-ante specific needs and priorities coming from local specializations and local communities needs (in other words "place based").

A "spatial-concentration" should produce a map of cohesion programming based on clear and informed decisions expressing the awareness of 'where' to invest in order to maximize effects of cohesion policies.
There is not a ex-ante solution in order to ensure the achievement of regional development results but a balance between a thematic generalization of objectives and a concrete spatial awareness of development precondition should be investigated.

The contribution of 'open data' to the impact assessment of EU Operative Programs appears to be mature in concept, but still weak in accuracy of available data bases.

For the present research we used data from 'Open Cohesion' project by Italian Ministry for Territorial Cohesion. The Italian Ministry engaged with this unstoppable process of collecting and sharing data to improve citizens commitment on public policies.

It developed a web service distributing data on investments policies developed by National and Regional Operative Programs 2007/2013 matching together data from regional and national administrations.

The results are analysed in paragraph number four of the paper with the application of spatial analysis techniques for the evaluation of spatial effects.

In this paper, a process of territorial impact assessment of Regional Operative Programs investments oriented to the analysis of territorial specialization in attracting funds has been described.

The process is completely based on Open Data analysis through Open Tools (software and web services) in order to demonstrate that the integration of such resources overcomes the dependence from proprietary data formats and proprietary software towards interoperability and open information.

The application concerns internal areas of Basilicata Region: Agri river Valley. A complex context, where environmental and agricultural traditional vocations conflict with a recent development of oil extraction industries.

* Corresponding author 
Conclusions concern possible applications and perspectives to improve and support regional development planning considering the exploitation of open data sources and spatial analysis.

\section{SPATIAL DATA, SPATIAL DATA INFRASTRUCTURES, OPEN DATA, OPEN- GOVERNMENT, OPEN-COHESION}

Until the end of 1980's spatial data production was mainly concentrated in national organizations. In subsequent years the increase of computer performance, according to Moore's law, the decrease of GIS software prices and the increase of GIS software functions (Longley, et al. 2001) generated a huge production of spatial data, because many organizations or single local authorities departments started to develop their own data. Consequently, an equally a drastic reduction in production costs of spatial information does not correspond to a huge reduction of system implementation costs.

The cause of this phenomenon is mainly due to a poor practice to share data, which generates a multiplication of resources to produce the same data.

Trying to solve this problem in 1994, Clinton's administration, with Executive Order 12906 (1994) "Coordinating Geographic Data Acquisition and Access: The National Spatial Data Infrastructure" (NSDI), established "the national data spatial infrastructure" with the aim of defining technologies, policies, standards and human resources necessary to acquire, process, store, distribute and improve the use of geospatial data.

Based on this Executive Order, all institutions and federal agencies documented all new geographic data using standards developed by the "Federal Geographic Data Committee" and made them accessible to the "National Geospatial Data Clearinghouse", to the network of producers, managers and all potential users of spatial data.

In addition to a redundant data production, a proliferation of GIS applications with very limited potential, often developed within the organization, occurred in the same period creating technological barriers in data exchange.

In order to solve interoperability problems an international consortium, Open Geospatial Consortium, completely dedicated to these problems, has been created. Open Geospatial Consortium (OGC) standards provide access through the internet to georeferenced data integrating local and remote data. Spatial data can be loaded by a simple Internet browser, or by a GIS software supporting OGC standards: Web Mapping Service (WMS), Web Feature Service (WFS), Web Coverage Service (WCS).

The European approach to spatial data infrastructures is based on INSPIRE (INfrastructure for SPatial InfoRmation in Europe) Directive. The Directive can be summarized in six principles:

1. Data should be collected once and maintained at the level where this can be done most effectively;

2. it should be possible to combine seamlessly spatial information from different sources across Europe and share it between many users and applications;

3. it should be possible for information collected at one level to be shared between all different levels, detailed for detailed investigations, general for strategic purposes;

4. geographic information needed for good governance at all levels should be abundant under conditions that do not refrain its extensive use;

5. it should be easy to discover which geographic information is available, fits the needs for a particular use and under which conditions it can be acquired and used;
6. geographic data should become easy to understand and interpret because it is properly documented and can be visualized within the appropriate context selected in a user-friendly way.

Rifkin (2000) highlights that, in the Internet age, "reticular economy" approaches have been developed with a transition from the markets intended as a physical place, centres of goods and properties trade, to virtual markets, mainly based on information transfers.

Consequently there is a trend towards an economy that prefers information collection to accumulation of physical capital. This trend indicates that information is a public good, which the State must guarantee for the benefit of the entire community, as if it were a financial resource (Rey, 1999).

Today data represent a big economic potential not exploited at all, because if data are available to everyone, they could create new companies and business growth for existing enterprises. A radical change in geographical information approach is necessary, based on OGC standards adoption and on implementation of INSPIRE directive.

Data have to be managed and updated by the organization that has the legal responsibility and have to be shared using OGC standards.

Using a parallelism with music it is important to pass from the gramophone, still in vogue, or Napster syndrome, based on the accumulation of terabytes and terabytes of data, to a Spotify approach.

If all geographic data produced with public resources are available online, offering the possibility to integrate remote and local data on your computer there is no longer the need to download data.
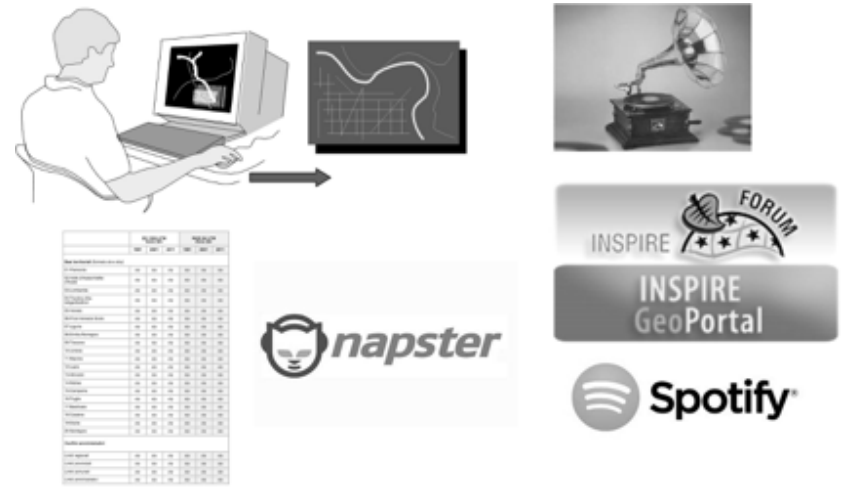

Spotify

Figure 1. Parallelism between the different approaches that characterize the various eras of geographic information and music (Murgante, 2014).

INSPIRE Directive and OGC standards are e-Government measures, very useful in providing faster and more efficient services through the rational use of technologies.

This approach considers the information flowing only in one direction from administration to citizens, ignoring communities potential contribution.

It is important to move from e-Government to e-Governance, where the information flow from citizens to the administration is also contemplated. In recent years the distance between citizens and government has increasingly enlarged. Consequently community failing to be an active part in administrative activity becomes the antagonist of public administration, without understanding that both should converge towards the same goal.

The right approach is to tend towards Open-Government policies based on a more participative method of government. It 
starts from the assumption that ideas of citizens have always to be collected, not only before elections.

Consequently, public involvement, getting ideas and suggestions, is a daily activity aiming to have a wider inspiration in managing and to collect feedback in already started actions. Obama's administration has given a great impetus to this approach, implementing such a policy and enlarging the possibility to capture public imagination by means of social networks, blogs and all possible solutions to directly interact with citizens.

This new approach is often called Gov. 2.0. Open government without a 2.0 approach is still based on a direct action. "Providers" is a sort of Right to Information where the administration tries to inform people, but having interaction just with the main stakeholders. Gov. 2.0 is a more open approach, which "enables" citizens to have an important role in defining policies.

Social media and all 2.0 platforms are a key element in generating a direct contact with citizens. Extension of 2.0 philosophy completely changed the relationship between citizens and administration.

People directly provide in realizing services that public administration is not interested to carry out and private sector does not consider convenient to realize.

The central elements of Open-Government are therefore participation, openness and sharing data. In US experience Open-Government (Obama, 2009) was based on three main principles: Transparency, Participation and Collaboration.

A central element in Open-Government becomes Open-Data. Each type of activity is based on data; it is therefore essential to promote these activities where great part of data is "Open", especially public ones.

To ensure that data are really "open" they should be open and not in proprietary format, without any particular constraints of licenses, reusable and integrable, easily searchable on the web through databases, catalogues and search engines, directly accessible through Internet protocols, quickly, immediately and at any time accessible by network, communicable and directly interchangeable on network between all users.

Data must also be equipped with metadata and they should allow export, on-line and off-line use, integration, manipulation and further share, they should also be readable by any operating system.

Generally speaking, Open Data means a file upload in portable document format (pdf) on a website allowing the download. This approach is located at a lowest level of Tim Berners-Lee (2009) Open Data classification according to stars scoring.

Two stars are assigned to data in property format, for which the owner, allowed a total utilization with some interoperability problems if you are not using the specific software.

Three stars are assigned to the product in non-proprietary format ("open format"). Data are in four-stars format if they follow international standards for interoperability, while fivestars data are to transfer also the meaning ("Open Linked Data").

Concerning territorial purpose, five stars open linked data include the adoption of OCG standards.

Open-Government and Open-Data represent two faces of the same coin.

The project 'Open Cohesion' provides an open data service concerning cohesion policies effects related to planning processes.

The initiative was strongly supported by the Minister for Territorial Cohesion, which stimulated a more active citizens participation in decision-making producing also a process of social vigilance on the use of collective resources.
Publication of data in an accessible format and reusable on their corporate websites shows the willingness of the government to move in a systematic way towards a structure of transparency that encourages active participation of citizens and re-use of data.

The service pursues the objective to improve Citizen Engagement on investments policies, and offers a data set with specific information concerning projects funded by the current programming period 2007-2013, matching implementation data from regional and national administrations entitled Ops management.

Open Cohesion appears to be a result of an Open Governement approach. Data provided can be included in three stars open level of Tim Berners-Lee classification with the opportunity to achieve the spatial dimension through external elaboration. In this direction, previous researches demonstrated the added value of providing open spatial information concerning development programs.

We refer to the experience developed by PIT Marmo Platano Melandro (Basilicata - IT) during the EU programming period 2000-2006 with a web gis service for the spatialization of development policies (Murgante et al. 2011).

While in that experience the main effort was in territorial data production, we have to affirm that today it is possible to develop accurate spatial analysis concerning the distribution of EU funded investments with public open data. In the next section we describe the adopted methodology.

\section{ANALYZING SPATIAL DIMENSION OF INVESTMENTS}

The innovative element of the proposed assessment is the punctual territorialisation of projects and interventions. It is beyond the traditional representation of information for aggregated items and pre-defined geographical areas (administrative boundaries, areas PIT, PIOT, program areas, etc..) according to the aim of characterizing "places of implementation."

The approach is based on open dataset distributed according to interoperable formats, managed by open-sources software and application, with a strong relationship with web-based services.

The issue of territorial impact assessment of development policies is a domain where different approaches produce different results that often represent solutions for a specific purpose, serving a specific process of socio-economic and territorial planning without a framework methodology validated under a scientific or technical point of view.

The developed proposal (Las Casas et al. 2016) aims to provide answers to the demand for territorial specialization analysis oriented to the construction of policy choices to be developed within the EU's 2014-2020 operational planning tools.

The proposed approach, based on information concerning the implementation of 2007-2013 instruments, develops an interpretation model that allows a progressive monitoring of ongoing processes. A territorial monitoring system that allows at detailed scale punctual information.

In fact, a procedure identifying punctual interventions (public and private projects in different thematic areas of intervention) through a dataset of geo-referenced points useful in developing spatial statistics, overlaying, compatibility assessments, etc. has been developed.

The territorial context of the implementation is the Agri river Valley, an inland area of the Basilicata Region where structural problems for socio-economic development related to a low level of infrastructures, to a fragmented distribution of settlements 
and services, to a backward and uncompetitive production system coexist.

In contrast to this condition of lagging area, since 1990s a settlement in oil extraction, relevant also at national level, has been planted (ENI, 2012).

These industrial activities, characterized by an high environmental impact, generated conflicts, even at local development programming level, compared to a traditional view of development related to the enhancement of environmental and agricultural domains, and social expectations, in terms of a positive impact on employment and income for local communities, not yet completely satisfied.

Considering the structure of information sources, the implemented procedure adopts only free available tools. The flow chart presented in the following figure exemplifies the process in terms of operational components.

The first stage of the process includes the operation of extraction, analysis and preparation of data for territorialisation. The datasets provided by the project Open Cohesion contain fields relating to the 'localization' of each record; it means addresses of each individual intervention funded by different programs/funds.

These are attributes that can have different levels of specialization in relation to the nature of the intervention, the type of expense, with the characteristics of the proposer or the beneficiary of resources.

Generally, the objective of intervention territorialisation is to get precise location of each initiative.

Therefore, we considered field "address" in addition to "name of the City" and "Postal Code" to generate a string "LOCATION" on which to perform an operation of geo-coding, supported by Google free tools.

Data tables, appropriately pre-processed, were uploaded within 'Google Fusion Table'1.

It is a web experimental application distributed within Google application 'Google Drive', to view and share large data tables. The application tool allows to:

- Show online large tables of data;

- Filter and synthesize information;

- Develop online graphs, maps, graphs or layouts;

- Management of multi-user and collaborative production data;

- Merge and cross several databases;

- Export geographic data format $(. \mathrm{kml})$ and other interoperable formats (.csv)

Therefore Google Fusion Table, working online, allows to perform a geo-coding on field "location" of the table, returning a map of points exported in KML format.

These files, as verified by the operator recursively in order to reduce the uncertainty in localization, after processing by Google Earth2, are exported in local .kml format and subsequently converted in .shp through an online tool distributed by Zonum Solutions3.

In this way you get data with a proper format, widely interoperable in GIS application software and web-GIS.

Figure 3 shows the investments supported by the Operational Programmes 2007/2013 falling within Val d'Agri (Agri river Valley) Area. GIS processing was carried out using open-source sowtfare Q-GIS4.

\footnotetext{
${ }^{1}$ http://www.google.com/drive/apps.html\#fusiontables

${ }_{1}^{1}$ https://support.google.com/fusiontables/answer/2571232?hl=it

2 http://www.google.it/intl/it/earth/index.html

3 http://www.zonums.com/online/kml2shp.php

4 http:/www.qgis.org/it/site/
}

The next figure shows the total of 551 projects localized in the study context. The proposed procedure allows to achieve high accuracy in punctual localization of interventions and projects.

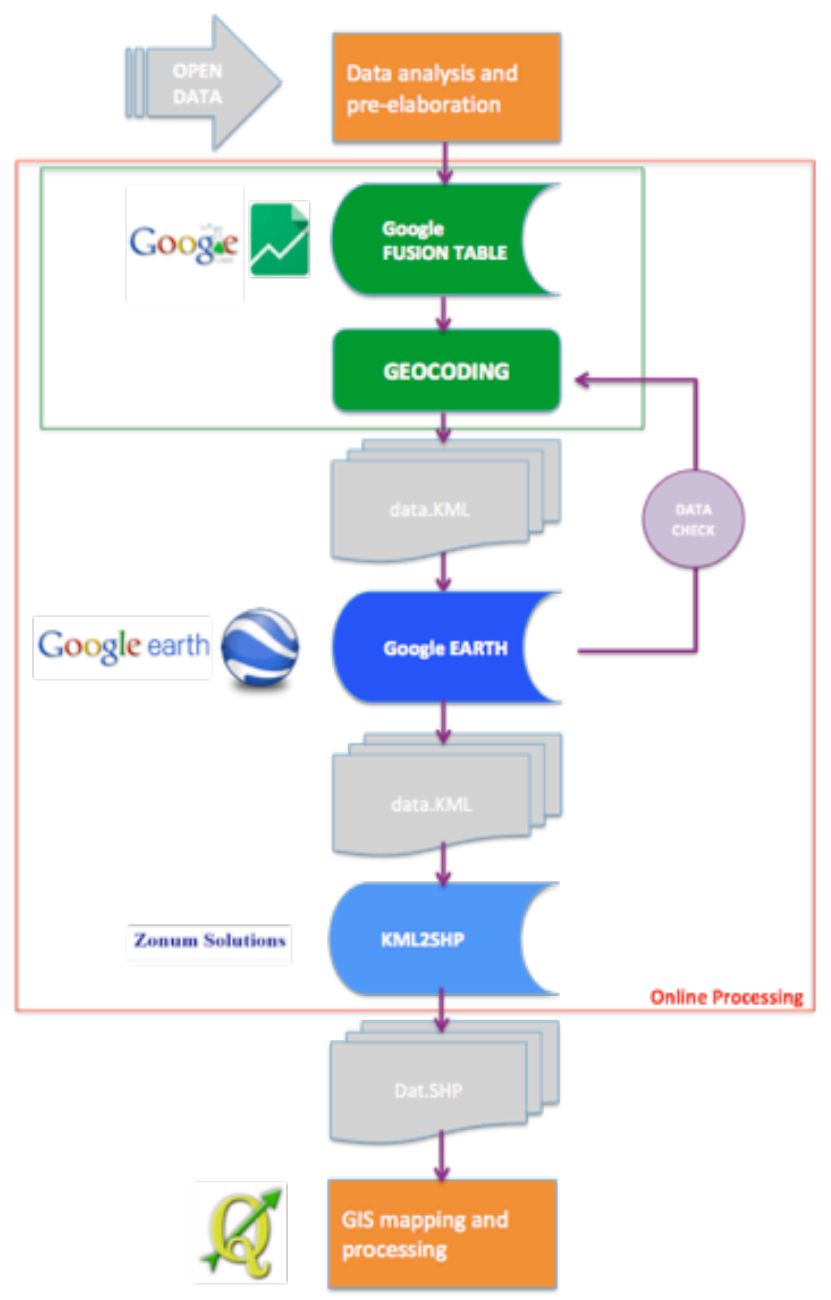

Figure 2. Territorialisation procedure flow chart.

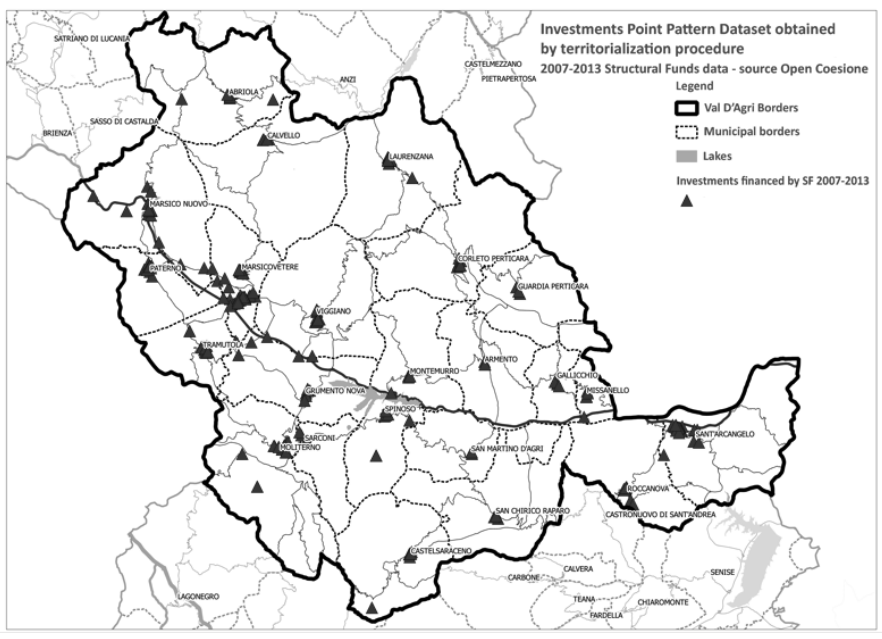

Figure 3. Investments point pattern in Agri Valley.

Table 1 describes the accuracy level and specific uncertainty causes in percentage. 


\begin{tabular}{|c|c|c|c|c|}
\hline $\begin{array}{c}\text { Orig } \\
\text { inal } \\
\text { Data } \\
\left(\mathrm{n}^{\circ}\right. \\
\text { reco } \\
\text { rds) }\end{array}$ & $\begin{array}{l}\text { Data } \\
\text { referred } \\
\text { to wider } \\
\text { administ } \\
\text { rative } \\
\text { area }\end{array}$ & $\begin{array}{l}\text { Localize } \\
\text { d by the } \\
\text { project' } \\
\text { address }\end{array}$ & $\begin{array}{l}\text { Localized } \\
\text { by the } \\
\text { name of } \\
\text { municipalit } \\
y\end{array}$ & $\begin{array}{l}\text { Not localizable } \\
\text { as errors affect } \\
\text { original data }\end{array}$ \\
\hline 100 & 8 & 76 & 9 & 7 \\
\hline & $\begin{array}{l}\text { These data } \\
\text { were } \\
\text { excluded } \\
\text { from } \\
\text { representat } \\
\text { ion as they } \\
\text { relate to } \\
\text { operations } \\
\text { for which } \\
\text { it is not } \\
\text { possible to } \\
\text { express a } \\
\text { point } \\
\text { impact }\end{array}$ & $\begin{array}{l}\text { The } \\
\text { geocoding } \\
\text { in Google } \\
\text { Fusion } \\
\text { Table and } \\
\text { the } \\
\text { subsequent } \\
\text { verificatio } \\
\mathrm{n} \text { in } \\
\text { Google } \\
\text { Earth } \\
\text { allow the } \\
\text { unique } \\
\text { identificati } \\
\text { on of the } \\
\text { investment } \\
\text { point }\end{array}$ & $\begin{array}{l}\text { Where the } \\
\text { address was } \\
\text { not } \\
\text { recognizable } \\
\text { by Google, } \\
\text { location of the } \\
\text { investment has } \\
\text { been fixed on } \\
\text { the main urban } \\
\text { centre of the } \\
\text { municipality }\end{array}$ & $\begin{array}{l}\text { In the operational } \\
\text { phase cases in which, } \\
\text { on the basis of the } \\
\text { information } \\
\text { contained in the } \\
\text { attributes of projects } \\
\text { location, it was not } \\
\text { possible to make an } \\
\text { unambiguous choice } \\
\text { of location have been } \\
\text { reported. For } \\
\text { example, it has been } \\
\text { found several times } \\
\text { that in the address } \\
\text { field of a project an } \\
\text { information referring } \\
\text { to a location } \\
\text { belonging to a } \\
\text { municipality that did } \\
\text { not correspond with } \\
\text { project municipality } \\
\text { was presented. }\end{array}$ \\
\hline
\end{tabular}

Table 1. Accuracy of territorialisation process.

The information structure obtained allows to build several maps and elaboration that are exemplified here.

The first representation is based on a traditional function of GIS that allows to proportionally represent total financing of each project by a precise symbolism.

The result of processing allows a visualization of concentration of investments.

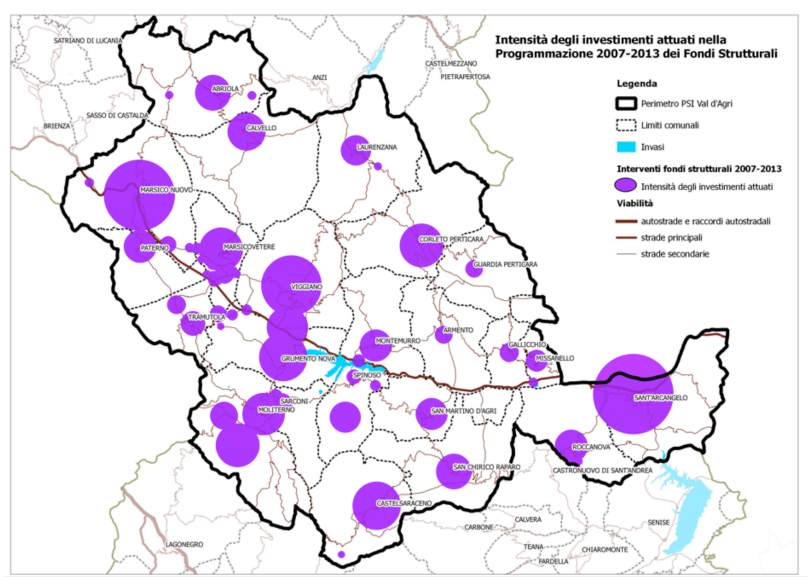

Figure 4. Intensity of public financing.

Considering the whole study area it is evident that the territorial structure of Agri river Valley presents a fragmented behaviour, mainly concentrated in two main polarities: Villa d'Agri and Sant'Arcangelo municipalities.

Another measure of density refers to the calculation of Kernel density compared to localized operations dataset.

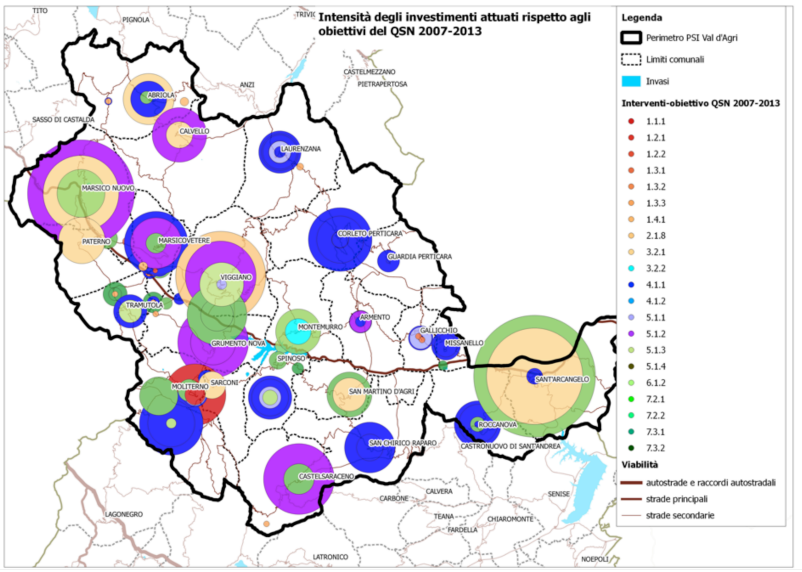

Figure 5. Classification of interventions.

This representation allows to recognize the territorial subsystems independent from traditional processing based on administrative areas.

More in particular, the axis formed by municipalities of Moliterno, Grumento Nova, Viggiano in the upper part of the Valley represents an effective polycentric structure where services, housing and productive investments are organized according to a logic of the district.

On the contrary, Kernel density measurement allows to discriminate poles of Marsicovetere, Marsico Nuovo, Sant'Arcangelo and Corleto Perticara, which have a centralizing behaviour of services and territorial functions.

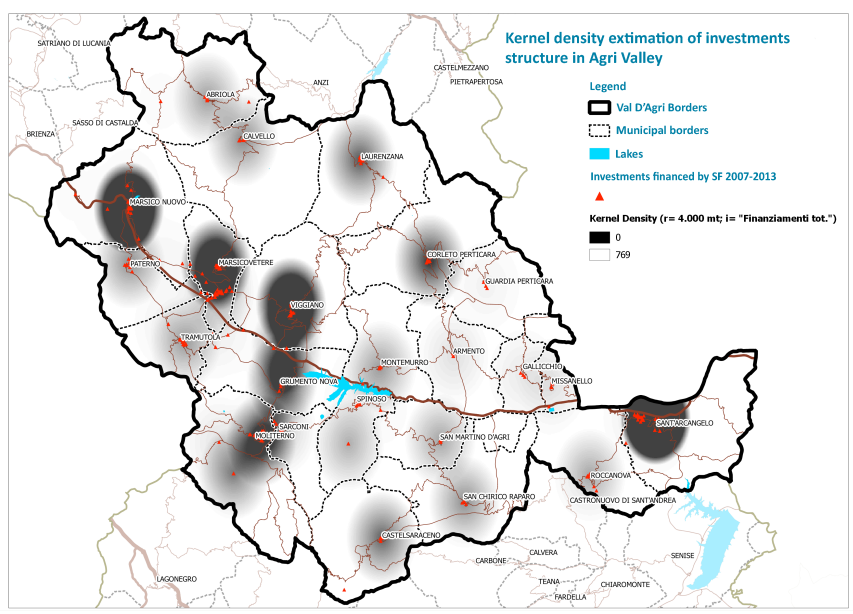

Figure 6. Investments (2007-2013) density assessment map.

The central part of Agri river Valley has low specialization in attracting investment and relies on development policies.

This represents a matter of planning more important in the perspective of the European programming period 2014-2020. Investments intensity mainly follows principal population agglomerations.

In such framework several planning concerns emerged in terms of development opportunities for peripheral sub-areas where we measured minimum population density and marked underdevelopment.

How is it possible to attract investment and to stimulate local development according to such structural weaknesses?.

One possible answer lies in the definition of strategic plans articulated in 'chains of actions' that balance the protection of natural and cultural resources with economic development. 
Among the main features described in this work the theme of energy has a dual perspective: on one side the idea of environmental balance between oil industries and Renewable Energy Sources, on the other the process of redevelopment of traditional form and manufacts of agricultural energy (i.e. ancient network of water-mills) as nodes of a network of community engagement including immaterial actions (knowledge and information dissemination, community involvement and participation, etc.) and investments in local welfare.

\section{CONCLUSIONS AND PERSPECTIVES}

Place based approach will bring to innovations in EU cohesion management. Where outcomes indicators measure the implementation of cohesion operative program (Barca et al. 2011), other efforts should be addressed to the identification of local specialization. It could generate not a fix picture of a context, places and communities continuously evolve, especially as a reaction to the huge changes brought by economic crisis.

Main issues connected with the instances of the New Cohesion Policies are:

- the need of a clear identification of the combined place-specific characteristics in each region;

- a clear identification of the appropriate territorial context in order to effectively implement "smart specializations".

Open data phenomena represent an useful process that already drove research from data production to exploitation of the informative value of several data sources available to everybody.

But data and data analysis technique cannot bring automatically to useful information. Regional science has the task to produce effective 'places' interpretation in order to support public decision in incoming generation of EU ROPs also concerning Urban Agenda considering bottom-up inclusive processes (Pontrandolfi P., Scorza F., 2016).

We are in the case where it is relevant to use numerous data sources and indicators assuming a variable rate of approximation in the accuracy of datasets.

Information management and exchange implies problems in interoperability among sources, procedures and technologies.

In the field of Regional development the ontological approach provided alternative interpretation models of the interaction among context, program and beneficiaries (Scorza et al 2012; Scorza et al. 2010).

Specialization analysis should be developed through an integrated set of techniques, oriented to generate descriptive geographies of EU regions at a variable scale (among recent studies: Amato et al. 2016).

The preliminary elaborations proposed in previous section highlight the potentialities of managing such structured datasets. The perspective concerns the application of such processes in the framework of managing Regional Operative Programs and generally "local development programs" in order to involve beneficiaries and citizens in the process. Another relevant issue is to inform the technical level on success or failure of a specific policy in order to improve the plan in terms of effectiveness and sustainability.

It is possible to affirm that a real time monitoring system of development investments is actually feasible with current open resources.

\section{REFERENCES}

About W3C Standards http://www.w3.org/standards/about.html

Amato, F., Maimone, B. A., Martellozzo, F., Nolè, G., \& Murgante, B., 2016, The Effects of Urban Policies on the Development of Urban Areas. Sustainability, 8(4), 297.

Barca F., 2009, An agenda for a reformed cohesion policy: a place-based approach to meeting European union challenges and expectations. Independent report prepared at the request of the European Commissioner for Regional Policy, Danuta Hübner, European Commission, Brussels

Barca F., McCann P., 2011, Methodological note: outcome indicators and targets-towards a performance oriented EU cohesion policy and examples of such indicators are contained in the two complementary notes on outcome indicators for EU2020 entitled meeting climate change and energy objectives and improving the conditions for innovation, research and development.

See: http://ec.europa.eu/regional_policy/sources/docgener/evaluation /performance en.htm, Accessed 1 October 2011 (2011)

Berners-Lee T. $5 \star$ Open Data http://5stardata.info/\#addendum4

Capello R., 2014, Smart Specialisation Strategy and the New EU Cohesion Policy Reform: Introductory Remarks, SCIENZE REGIONALI 2014, Fascicolo: 1, P.

EC, 2007, "Inspire Directive" http://eur-lex.europa.eu/ LexUriServ/ site/ it/ oj/ 2007/ 1_108/ 1_10820070425it00010014.pdf,

\section{ENI in Basilicata, Local Report (2012) ENI}

Executive Order 12906, 1994, http://www.archives.gov/federalregister/executive-orders/pdf/12906.pdf,

Las Casas, G., Scorza, F., 2016, Sustainable Planning: A Methodological Toolkit. In International Conference on Computational Science and Its Applications (pp. 627-635), Springer.

Las Casas, G., Murgante, B., Scorza, F., 2016, Regional Local Development Strategies Benefiting from Open Data and Open Tools and an Outlook on the Renewable Energy Sources Contribution. In Smart Energy in the Smart City (pp. 275-290). Springer International Publishing.

Longley, P A. Goodchild, M F. McGuire, D J., Rhind, D W., 2001, Geographic Information Systems and Science, John Wiley \& Sons, 2001.

Obama B., 2009, Memorandum for the Heads of Executive Departments and Agencies on Transparency and Open Government,

(http://www.whitehouse.gov/the_press_office/Transparencyand OpenGovernment/)

Open Government Initiative http://www.whitehouse.gov/open

Pontrandolfi, P., Scorza, F., 2016, Sustainable Urban Regeneration Policy Making: Inclusive Participation Practice. In O. Gervasi, B. Murgante, S. Misra, C. A. M. A. Rocha, C. Torre, D. Taniar, ... S. Wang (Eds.), Computational Science and Its Applications -- ICCSA 2016, Part III (pp. 552-560). Cham: Springer International Publishing. doi:10.1007/978-3319-42111-7_44 
Rey G.M., 1999, "L'informazione è un patrimonio come il denaro. Non sprechiamolo", in Telèma Burocrazia elettronica Società più civile, n.18 http://www.fub.it/telema/TELEMA19/Rey19.html （ultimo accesso 15/02/01)

Rifkin J., 2000, L'era dell'accesso Mondatori editore, Milano

Scorza F, Las Casas G., Murgante B., 2012, That's ReDO: Ontologies and Regional Development Planning, in Lecture Notes In Computer Science, 2012, VOLUME 7334/2012, 640652, DOI: 10.1007/978-3-642-31075-1_48 (2012)

Scorza F., Las Casas G., Murgante B. 2010, Overcoming Interoperability Weaknesses in e-Government Processes: Organizing and Sharing Knowledge in Regional Development Programs Using Ontologies in Lytras M.D., Ordonez De Pablos P., Ziderman A., Roulstone A., Maurer H., Imber J. B. (Eds), Organizational, Business, and Technological Aspects of the Knowledge Society, Communications in Computer and Information Science, 112, XXVII, pp. 243-253, SpringerVerlag, Berlin, ISSN: 1865-0929, DOI: 10.1007/978-3-64216324-1_26(2010)

Tilio L, Larosa S, Sansone A, Scorza F, Lanza V, Las Casas G, P. Pontrandolfi, Murgante B., 2009. E-gov tools for evaluation in programming processes. In: Rabino G., Caglioni M. eds. Planning, Complexity and New ICT, p. 167-177, FIRENZE: Alinea Editrice, ISBN: 9788860554154

Transparency International Georgia, Ten Open Data Guidelines, http://www.transparency.ge/en/ten-open-data-guidelines

Wendy R. Ginsberg The Obama Administration's Open Government Initiative: Issues for Congress https://www.fas.org/sgp/crs/secrecy/R41361.pdf 